\title{
Influence of Root Exudates on the Bacterial Degradation of Chlorobenzoic Acids
}

\author{
Blanka Vrchotová, Petra Lovecká, Milena Dražková, Martina Macková, and Tomas Macek \\ Department of Biochemistry and Microbiology, Faculty of Food and Biochemical Technology, Institute of Chemical Technology Prague, \\ Technicka 3, 16628 Prague 6, Czech Republic
}

Correspondence should be addressed to Tomas Macek; tomas.macek@vscht.cz

Received 6 August 2013; Accepted 3 September 2013

Academic Editors: T. Cajthaml and F. Fatone

Copyright (C) 2013 Blanka Vrchotová et al. This is an open access article distributed under the Creative Commons Attribution License, which permits unrestricted use, distribution, and reproduction in any medium, provided the original work is properly cited.

Degradation of chlorobenzoic acids (e.g., products of microbial degradation of PCB) by strains of microorganisms isolated from PCB contaminated soils was assessed. From seven bulk-soil isolates two strains unique in ability to degrade a wider range of chlorobenzoic acids than others were selected, individually and even in a complex mixture of 11 different chlorobenzoic acids. Such a feature is lacking in most tested degraders. To investigate the influence of vegetation on chlorobenzoic acids degraders, root exudates of two plant species known for supporting PCB degradation in soil were tested. While with individual chlorobenzoic acids the presence of plant exudates leads to a decrease of degradation yield, in case of a mixture of chlorobenzoic acids either a change in bacterial degradation specificity, associated with 3- and 4-chlorobenzoic acid, or an extension of the spectrum of degraded chlorobenzoic acids was observed.

\section{Introduction}

There are many different known and used methods for decontamination of polluted areas [1]. It is possible to use biological or physical or chemical methods or combination of them. Each of these approaches has its positive but also negative aspects (Table 1). In this paper use of biological method, microorganisms, and plant, for removal of chlorobenzoic acids (CBAs) is discussed.

CBAs are known as degradation products generated during the bacterial degradation of substances such as polychlorinated biphenyls (PCBs), DDT, and other chlorinated xenobiotics. Microbial degradation of such compounds can result in the formation of CBAs with different numbers and positions of chlorine atoms on an aromatic ring [2]. Degradation of CBAs and its parent compounds (e.g., PCBs) is usually performed by at least two different bacterial strains.

Microbial degradation of CBAs, as in the degradation of other chlorinated aromatic compounds, is confounded by the presence of chlorine atoms which interfere with the enzymatic breakdown of the aromatic ring. This problem can be overcome by the incorporation of a dehalogenation step at the beginning of the catabolic pathway as in the 4-CBA degradation pathway [3]. The first step of 4-CBA degradation is the conversion to 4-hydroxybenzoate by a hydrolytic process catalyzed by 4-chlorobenzoate dehalogenase with acetyl coenzyme A [3]. The hydrolytic process is followed by breakdown of the aromatic ring.

2-CBA can be degraded by two different degradation pathways. The most common is the spontaneous removal of chlorine and $\mathrm{CO}_{2}$ from 2-CBA during the 1,2-dioxygenase attack resulting in the formation of catechol. The second route is 1,6-dioxygenase attack resulting in the formation of 3chlorocatechol [4]. The formation of 3-chlorocatechol is followed by cleavage of the aromatic ring resulting in formation of chloromuconic acid followed by a dechlorination step [4].

Degradation of 3-CBA can be processed through a number of different degradation pathways. Formation of the 3-chlorocatechol or 4-chlorocatechol is catalyzed by the chlorobenzoate-1,2-dioxygenase [5]. Protocatechuate (3, 4-dihydroxybenzoic acid) or 5-chloroprotocatechuate (5chloro-3,4-dihydroxybenzoic acid) can be formed by the 3chlorobenzoate-3,4-dioxygenase [6]. Another possibility of the 3-CBA degradation is the formation of gentisate $(2,5-$ dihydroxybenzoic acid) with 3-hydroxybenzoic acid as an intermediate [7]. 
TABLE 1: Comparison of technologies used for decontamination of polluted areas [1].

\begin{tabular}{|c|c|c|c|}
\hline Technology & Description & + & - \\
\hline Bioremediation & $\begin{array}{l}\text { Use of plants and/or } \\
\text { microorganisms }\end{array}$ & $\begin{array}{l}\text { (i) In situ/ex situ } \\
\text { (ii) Cheap } \\
\text { (iii) Economical also for low } \\
\text { level contamination }\end{array}$ & $\begin{array}{l}\text { (i) Needs longer time } \\
\text { (ii) Contaminant specific }\end{array}$ \\
\hline \multicolumn{4}{|l|}{ Physical methods } \\
\hline Burning/dump site & $\begin{array}{l}\text { Excavation of the } \\
\text { contaminated soil and its } \\
\text { burning at high temperature } \\
\text { or deposition on a dump side }\end{array}$ & $\begin{array}{l}\text { (i) Ex situ } \\
\text { (ii) Fast } \\
\text { (iii) Possible to use for wide } \\
\text { spectra of contaminants }\end{array}$ & $\begin{array}{l}\text { (i) Destruction of } \\
\text { environment } \\
\text { (ii) Needs special equipment } \\
\text { (iii) Burning effective just for } \\
\text { organic contaminants }\end{array}$ \\
\hline Solidification/stabilization & $\begin{array}{l}\text { Immobilization of } \\
\text { contaminant on sorbent }\end{array}$ & $\begin{array}{l}\text { (i) In situ/ex situ } \\
\text { (ii) Fast }\end{array}$ & $\begin{array}{l}\text { (i) Possible rebounding } \\
\text { contaminant is present forever }\end{array}$ \\
\hline Electrokinetic remediation & $\begin{array}{l}\text { Removal of contaminants by } \\
\text { electromigration and } \\
\text { electroosmosis }\end{array}$ & $\begin{array}{l}\text { (i) In situ/ex situ } \\
\text { (ii) Fast } \\
\text { (iii) Organic and heavy metals }\end{array}$ & $\begin{array}{l}\text { (i) Needs special equipment } \\
\text { (ii) Not possible to use for all } \\
\text { types of soils }\end{array}$ \\
\hline Washing/flushing & $\begin{array}{l}\text { Use of water or detergent } \\
\text { solution for washing of } \\
\text { contaminants }\end{array}$ & $\begin{array}{l}\text { (i) In situ/ex situ } \\
\text { (ii) Possible to use for wide } \\
\text { spectra of contaminants }\end{array}$ & $\begin{array}{l}\text { (i) Needs special equipment } \\
\text { (ii) Need of decontamination } \\
\text { of the resulting solution }\end{array}$ \\
\hline \multicolumn{4}{|l|}{ Chemical methods } \\
\hline Oxidation & $\begin{array}{l}\text { Application of strong oxidants } \\
\text { (hydrogen peroxide, } \\
\text { potassium permanganate } \\
\text { ozone gas, or persulfates) }\end{array}$ & $\begin{array}{l}\text { (i) In situ/ex situ } \\
\text { (ii) Fast }\end{array}$ & $\begin{array}{l}\text { (i) Only for organic } \\
\text { contaminants } \\
\text { (ii) Destruction of the present } \\
\text { ecosystems }\end{array}$ \\
\hline Hydrolysis & Mostly alkaline hydrolysis & $\begin{array}{l}\text { (i) In situ/ex situ } \\
\text { (ii) Fast }\end{array}$ & $\begin{array}{l}\text { (i) Only for organic } \\
\text { contaminants } \\
\text { (ii) Destruction of the present } \\
\text { ecosystems }\end{array}$ \\
\hline
\end{tabular}

In the case of dichlorinated CBAs, degradation proceeds mostly by a 1,2-dioxygenase attack [8]. Another option for degradation of dichlorinated CBAs includes the complete removal of chlorine atoms via a two-step process prior to aromatic ring cleavage like in 2,4-CBA degradation or a 3,4-dioxygenase attack like in 3,4-CBA degradation. The two steps of chlorine removal in 2,4-CBA degradation are reductive dechlorination leading to the formation of 4-CBA and hydrolytic dechlorination. The degradation of 3,4-CBA is initiated by a 3,4-dioxygenase attack resulting in the formation of 5-chloroprotocatechuate [4].

As described, there is a wide variety of CBA degradation pathways which leads to the possibility that different CBAs can be degraded by one bacterial strain with enzymes from more than one route. These enzymatic pathways may potentially be induced by plant secondary compounds, root exudates, or the other CBAs presented [9].

This precondition was investigated by testing microbial CBAs degradation abilities of strains previously isolated from PCB contaminated soils. Three bacterial strains were isolated from soil collected at the paint company COLORLAK in Uherské Hradiště (UH strains) [10] and four strains from Žamberk company ZEZ SILKO (A strains) [11]. These experiments test the degradation activity of strains by growth on multiple different individual CBAs. This degradation potential was then compared with the degradation potential determined in the set of tests with a mixture of all eleven tested CBAs. In addition to the testing of degradation abilities, the impact of plant exudates, prepared by hydroponic cultivation of tobacco (Nicotiana tabacum) or black nightshade (Solanum nigrum) plants, on degradation of individual CBAs or a mixture of eleven CBAs was determined.

\section{Materials and Methods}

2.1. Chemicals. Chlorobenzoic acids (2-CBA;3-CBA; 4-CBA; 2,3-CBA; 2,4-CBA; 2,5-CBA; 2,6-CBA; 3,4-CBA; 3,5-CBA; 2,3,5-CBA, and 2,4,6-CBA) were obtained from SigmaAldrich. All chemicals used in the cultivation media were of analytical reagent grade. Mobil phases used for liquid chromatography were of HPLC gradient grade.

2.2. Bacterial Strains. Bacterial strains were previously isolated from PCBs contaminated soil from two different locations in the Czech Republic. Strains A7, A8, A18, and A19 were obtained from Žamberk soil contaminated with a PCB mixture Delor 103 of $300 \mathrm{mg}$ per kg dry soil [11]. Strains UH82, UH133, and UH222 were from Uherské Hradiště soil containing $0-470 \mathrm{mg}$ of total PCBs per gram dry weight of soil [10]. Strains A7 and A8 were identified as Pseudomonas fluorescens, strain A18 as Pseudomonas pseudoalcaligenes, and 


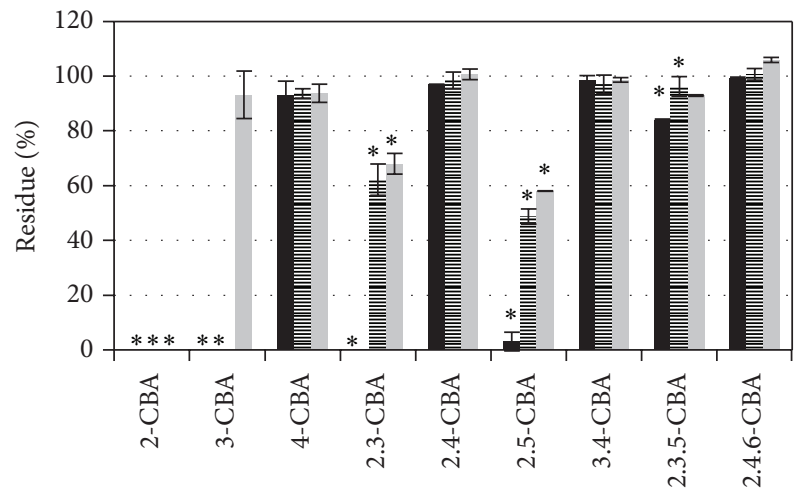

(a)

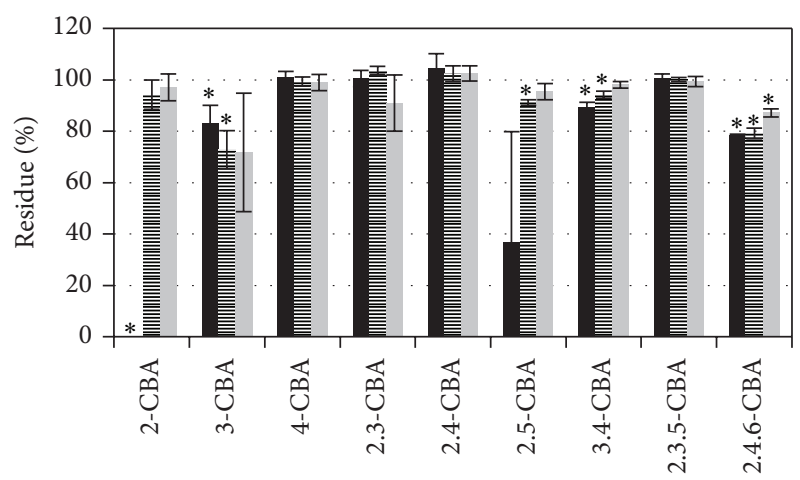

(c)

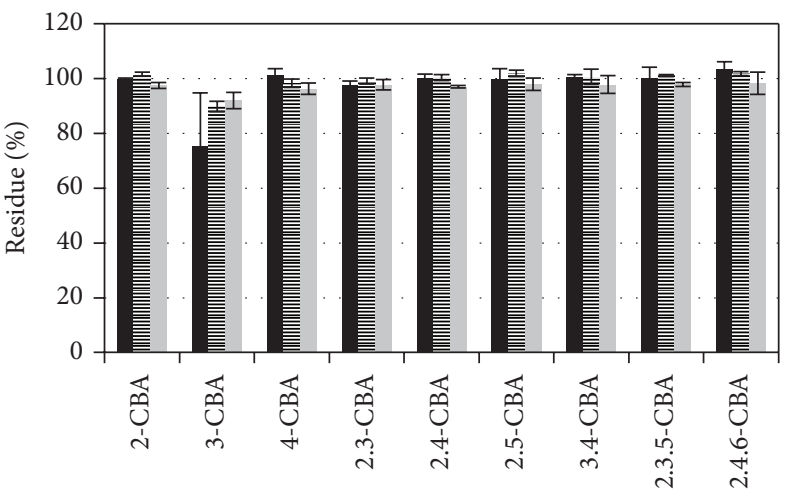

(b)

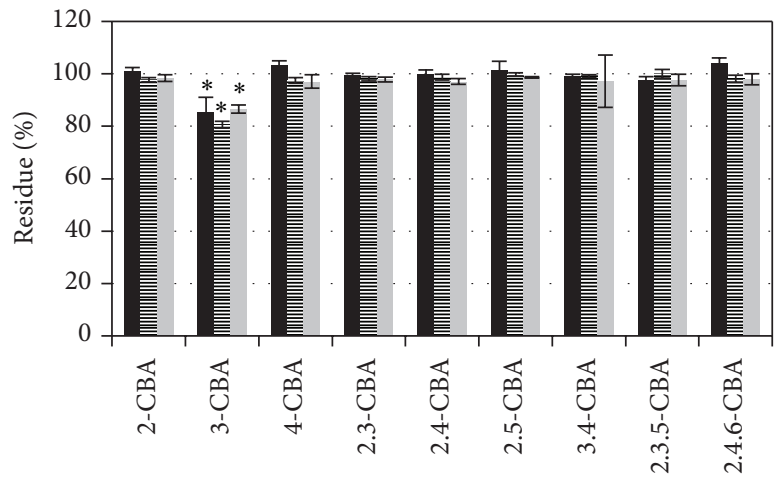

(d)

Figure 1: Degradation of single CBA ((a), (c)) and mixture of CBA ((b), (d)) by strains A7 (Pseudomonas fluorescens) ((a), (b)) and A8 (Pseudomonas fluorescens) ((c), (d)). Black bar in minimal medium, stripped bar in minimal medium with exudates of black nightshade (Solanum nigrum), and grey bar in minimal medium with exudates of tobacco (Nicotiana tabacum). Stars indicate the statistically significant CBA removal (ANOVA).

strain A19 as Pseudomonas stutzeri [11]. Strains UH133 and UH222 from Uherské Hradiště were classified as Pandoraea sp.; strain UH82 was identified as Arthrobacter sp. [10].

\subsection{Preparation of Plant Root Exudates. Plant root exudates} were prepared from both plant species according to the same procedure. One-month-old plants grown in soil were washed with water and with sterile tenth-strength minimal media $\left(3.5 \mathrm{gL}^{-1} \mathrm{~K}_{2} \mathrm{HPO}_{4} ; 1.5 \mathrm{~g} \mathrm{~L}^{-1} \mathrm{KH}_{2} \mathrm{PO}_{4} ; 0.5 \mathrm{gL}^{-1}\right.$ $\mathrm{NH}_{4} \mathrm{Cl} ; 0.5 \mathrm{~g} \mathrm{~L}^{-1} \mathrm{NaCl} ; 0.14 \mathrm{~g} \mathrm{~L}^{-1} \mathrm{Na}_{2} \mathrm{SO}_{4} ; 0.07 \mathrm{~g} \mathrm{~L}^{-1} \mathrm{MgCl}_{2}$ ). Stem of the plant was wrapped with gaze stopper above the roots and placed into a $250 \mathrm{~mL}$ Erlenmeyer flask with $200 \mathrm{~mL}$ of tenth-strength minimal medium. As shade aluminum foil covered the bottom and sides of the flask to the level of the medium. These prepared plants were hydroponically cultivated in 16-hour day light in $24^{\circ} \mathrm{C}$ for one month. Losses by evaporation were refilled with distilled water. Collected solutions containing root exudates were combined, and mineral salts were added to the solution to obtain full minimal medium with plant root exudates. Medium was filter-sterilized and stored at $4^{\circ} \mathrm{C}$. This way of root exudates preparation was chosen to obtain plant exudates profile most similar to soil-grown plants.

2.4. Cultivation Experiments with Different CBAs. Bacterial strains were cultivated in liquid minimal medium with the addition of $200 \mathrm{mg} \mathrm{L}^{-1}$ of benzoic acid on a rotary shaker $(130 \mathrm{rpm})$ at $28^{\circ} \mathrm{C}$. After two days cells were harvested by centrifugation $(10 \mathrm{~min} 5000 \times \mathrm{g}$ ) and washed twice in minimal medium. Degradation of CBA was measured in $8 \mathrm{~mL}$ glass vials. The total volume of the cultivation mixture was $2 \mathrm{~mL}$. The mixture consisted of either single CBAs $\left(200 \mathrm{mg} \mathrm{L}^{-1}\right)$ or a mixture of $11 \mathrm{CBAs}\left(20 \mathrm{mg} \mathrm{L}^{-1}\right.$ of each $\mathrm{CBA})$, bacteria $\left(\mathrm{OD}_{600}=0.4\right)$, and either minimal medium or minimal medium with root exudates from tobacco or black nightshade. CBA concentrations were measured by HPLC at time zero and after 5 days of bacterial cultivation. Sample of medium was centrifuged before measurement on HPLC $(6 \mathrm{~min} . \times 10000 \mathrm{~g})$ and stored at $-18^{\circ} \mathrm{C}$. CBA degradation was expressed as the difference between the initial concentration and the concentration of CBA in the medium after 5 days of cultivation. As a control, appropriate medium with the addition of CBA without bacteria was used. For the removal of outliers the Dean Dixon test $(\alpha=0.05)$ was used. Degradation was evaluated by comparison with control by one way ANOVA (with 90\% significance).

2.5. HPLC Analysis of CBA Concentration. The concentration of added CBAs was quantified by reverse phase high pressure liquid chromatography (HPLC) (Hewlett Packard model 1100) computer operated system with Chemstation program. HPLC analytical procedures employed column 


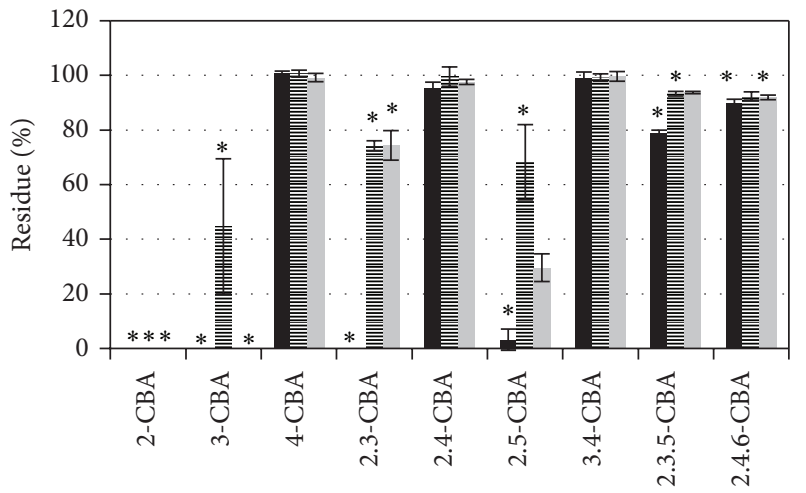

(a)

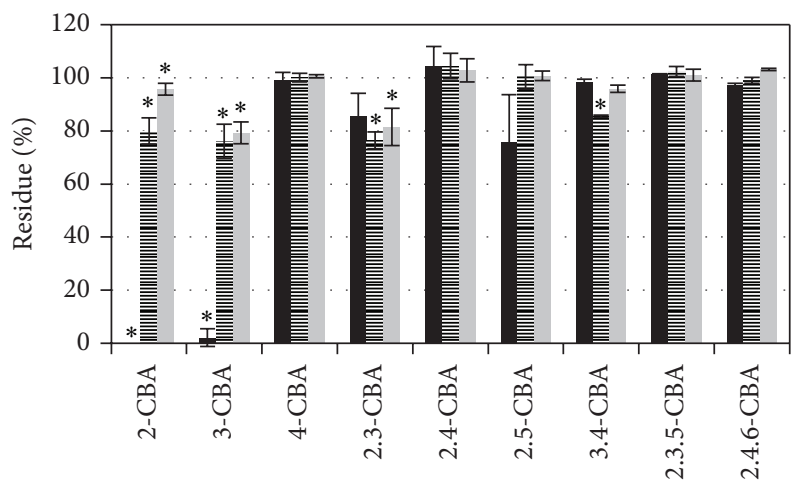

(c)

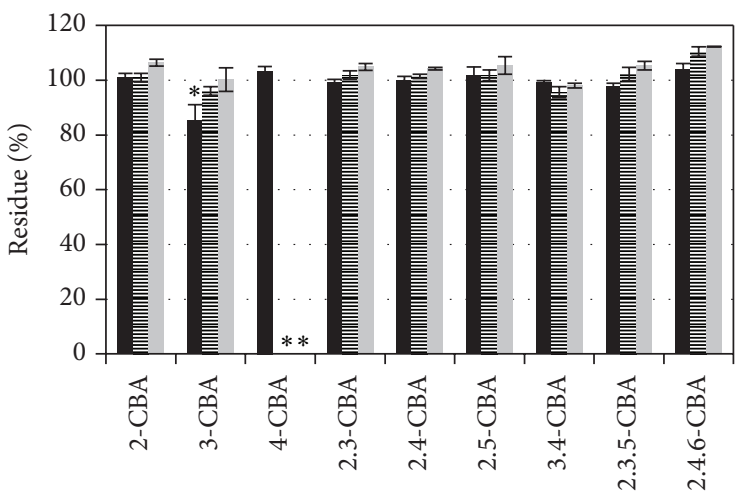

(b)

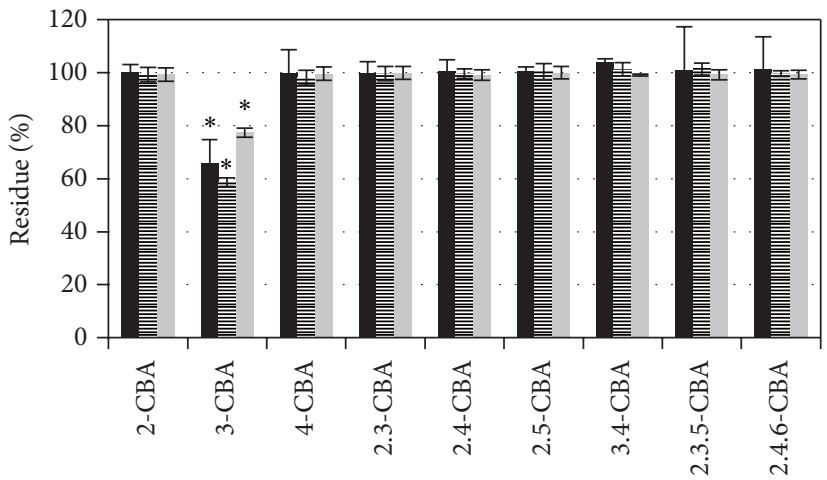

(d)

Figure 2: Degradation of single CBA ((a), (c)) and mixture of CBA ((b), (d)) by strains A18 (Pseudomonas pseudoalcaligenes) ((a), (b)) and A19 (Pseudomonas stutzeri) ((c), (d)), Black bar in minimal medium, stripped bar in minimal medium with exudates of black nightshade (Solanum nigrum), and grey bar in minimal medium with exudates of tobacco (Nicotiana tabacum). Stars indicate the statistically significant CBA removal (ANOVA).

LUNA C18(2) $150 \mathrm{~mm} \times 2.00 \mathrm{~mm} \times 5 \mu \mathrm{m}$ (Phenomenex, USA). Isocratic elution with mobile phase methanol (water $1 \%(v / v) \mathrm{H}_{3} \mathrm{PO}_{4} 60: 40$ for 2,3,5-CBA and 2,4,6-CBA and $55: 45$ for other CBAs) was used. Mobile phase flow rate was $0.4 \mathrm{~mL} \mathrm{~min}^{-1}$, injection volume $10 \mu \mathrm{L}$, and the detection on DAD detector at the wavelength $205 \mathrm{~nm}$. For HPLC measurement of CBA mixture, column Kinetex C18 100A $150 \mathrm{~mm} \times 2.10 \mathrm{~mm} \times 2.6 \mu \mathrm{m}$ (Phenomenex, USA) was used with mobile phase that consisted of $45: 55$ methanol : buffer $\mathrm{pH} \quad 3.18$ (41.8 $\mathrm{mmol} \mathrm{L}^{-1} \mathrm{H}_{3} \mathrm{PO}_{4} ; 55.8 \mathrm{mmol} \mathrm{L}^{-1} \quad \mathrm{H}_{3} \mathrm{BO}_{3}$; $50.0 \mathrm{mmol} \mathrm{L}^{-1} \mathrm{NaOH}$; $\left.55.1 \mathrm{mmol} \mathrm{L}^{-1} \mathrm{CH}_{3} \mathrm{COOH}\right)$ and flow rate $0.15 \mathrm{~mL} \mathrm{~min}^{-1}$. All other parameters were the same as those previously described.

\section{Results and Discussion}

3.1. Degradation of Single CBA. Strains from Žamberk soil were able to degrade a greater variety of CBAs than strains from Uherské Hradiště when CBAs were supplied individually. Strains from Žamberk can be divided into two groups with similar degradation profiles: the first group containing strains A7 and A18 and the second consists of strains A8 and A19 (Figures 1 and 2).

Most of the strains from Uherské Hradiště degraded only 3-CBA except strains UH82 and UH222 (Figures 3 and 4). Strain UH82 degraded only 4-CBA (Figure 3). Strain UH222 in addition to the 3-CBA partially degraded also 2,3-CBA and 2,4,6-CBA. Degradation of 2,6-CBA and 3,5-CBA is not shown in pictures because of no degradation in all tested possibilities.

Earlier research has focused on the abilities of different bacterial strains to degrade various CBAs individually added [4] or in a combination of CBAs that consisted of no more than three CBAs $[12,13]$. These tests showed that some microbial strains can grow on a wide range of monohalogenated and dihalogenated CBAs $[4,14,15]$. Several strains can also use trihalogenated CBAs as the sole carbon source $[4,12,16]$.

Tested strains proved a high heterogeneity of CBAs degradation ability when CBAs were supplied individually and served as a sole source of carbon and energy. Under these conditions a slight degradation activity of trichlorinated CBAs was also registered. Strains A7 and A18 degraded 2,3,5CBA, and strains A8, A18 and UH222 degraded 2,4,6-CBA.

Based on the results it can be concluded that degradation of CBAs with chlorine in -ortho position like 2-CBA, 2,3$\mathrm{CBA}$, and 2,5-CBA was very common and degradation of 3CBA was more frequent then degradation of 4-CBA. On the contrary degradation of CBAs with chlorine atoms in both -ortho positions (2,6-CBA or 2,4,6-CBA) was very rare, the same as degradation of CBAs with chlorines in both -meta positions (3,5-CBA and 2,3,5-CBA). 


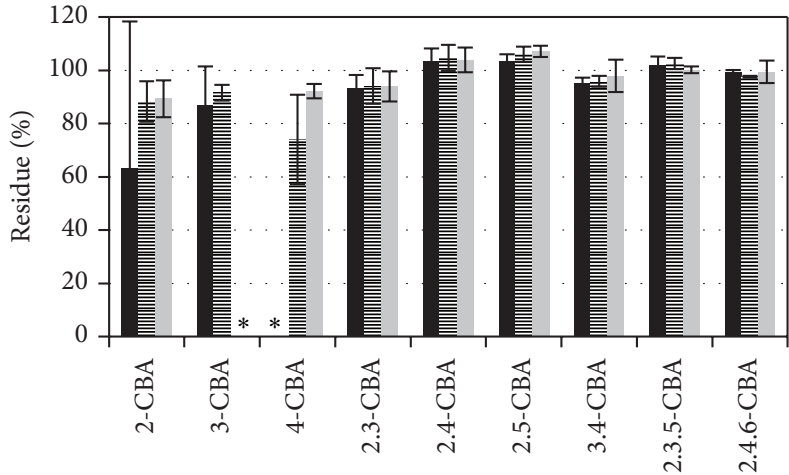

(a)

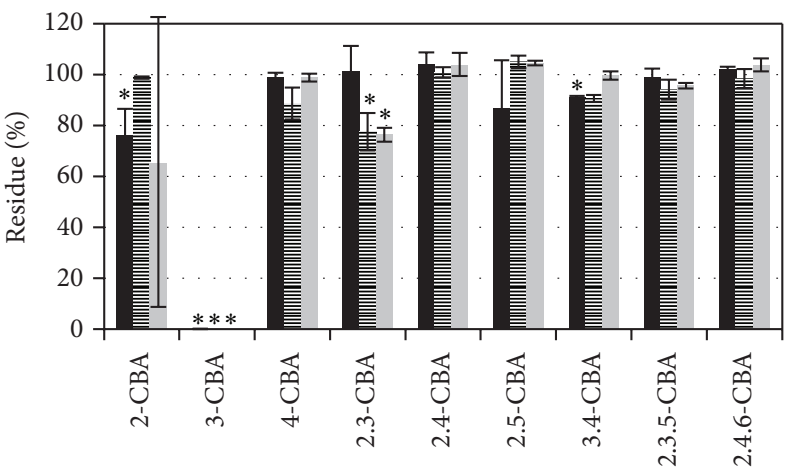

(c)

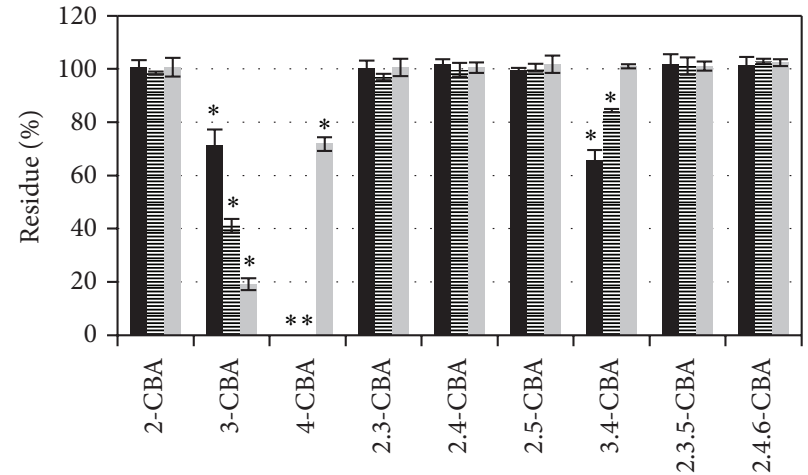

(b)

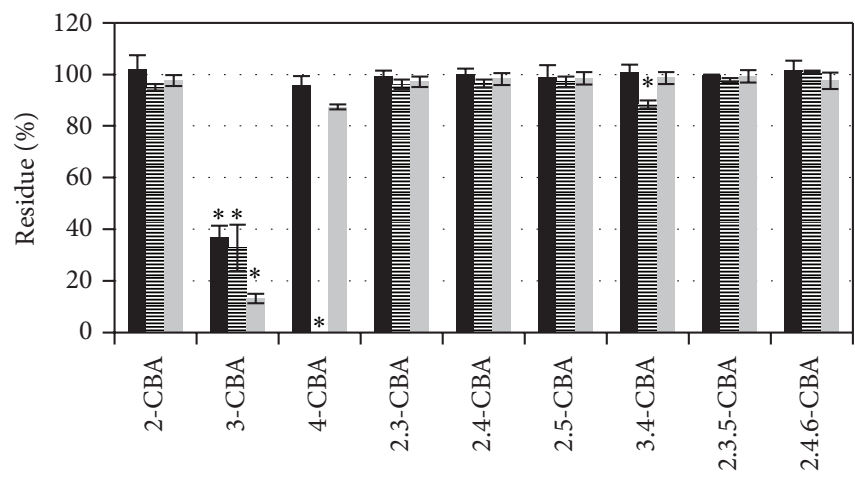

(d)

Figure 3: Degradation of single CBA ((a), (c)) and mixture of CBA ((b), (d)) by strains UH82 (Arthrobacter sp.) ((a), (b)) and UH133 (Pandoraea sp.) ((c), (d)). Black bar in minimal medium, stripped bar in minimal medium with exudates of black nightshade (Solanum nigrum), and grey bar in minimal medium with exudates of tobacco (Nicotiana tabacum). Stars indicate the statistically significant CBA removal (ANOVA).

3.2. Degradation of CBA Mixture. The second part of this work was a comparison of the degradation potential assessed in individual CBA degradation tests with results obtained by testing bacterial growth on a mixture of eleven CBAs. To the authors knowledge, this type of measurement was never done previously for bacteria except in a study assessing the degradation potential of ligninolytic fungi [17].

When CBAs are present in a mixture, some of them can cause inhibition of degradation of other CBAs present. The presence of 3,5-CBA completely inhibited growth of Pseudomonas putida P111 on 2-CBA, 2,3-CBA, 2,4-CBA, 2,5CBA, and 2,3,5-CBA [12]. Also, the presence of 2,6-CBA slowed down 4-CBA degradation, while 2,3-CBA and 3,4CBA completely inhibited the degradation of 4-CBA [18].

Effect of certain CBAs on the degradation of other CBAs is difficult to determine in this study because all eleven CBAs were tested together. Degradation tests with the mixture of eleven CBAs showed that the number of degraded CBAs was mostly reduced in comparison with the number of degraded CBAs in tests where CBAs were added individually. The most sensitive strains (from the point of the decrease of degradation) were strains A7 and A8 (Figure 1).

On the contrary, due to the presence of other CBAs, in the mixture can be same CBA degraded co-metabolically [16]. Induction effects on CBA degradation can be seen in strain
UH82. In individual CBA degradation tests, strain UH82 degraded only 4-CBA; however, in degradation test with the mixture of CBAs the strain UH82 degraded 3-CBA and 3,4CBA in addition to 4-CBA (Figure 3 ).

From the results of mixture degradation it is possible to conclude that in tested strains degradation ability of 3-CBA is most stable. In individual tests all strains except UH82 proved 3-CBA degradation, and in mixture CBAs degradation, five strains preserved 3-CBA degradation ability.

\subsection{Impact of Plant Root Exudates on CBA Degradation} Potential. Microbial degradation potential of xenobiotics can be affected by abiotic factors (composition of pollutants), as well as by biotic factors, including the influence of other organisms present in the environment. The presence of plants or plant secondary metabolites may affect the degradation of CBAs $[19,20]$. The plants themselves have the CBAs degradation potential $[21,22]$. Plants of Salix viminalis were able to remove at least $20 \%$ of 4 -CBA from cultivation medium [22]. Plant cell cultures of black nightshade and horseradish metabolized in 2 weeks more than $90 \%$ of 2 CBA, 20-40\% of 2,3-CBA, 2,4-CBA, 2,5-CBA, and 2,6-CBA at concentration of $50 \mathrm{mg} / \mathrm{L}$ [21].

The presence of plants can also increase CBA degradation by induction of microbial degradation $[13,23]$ or excretion of 


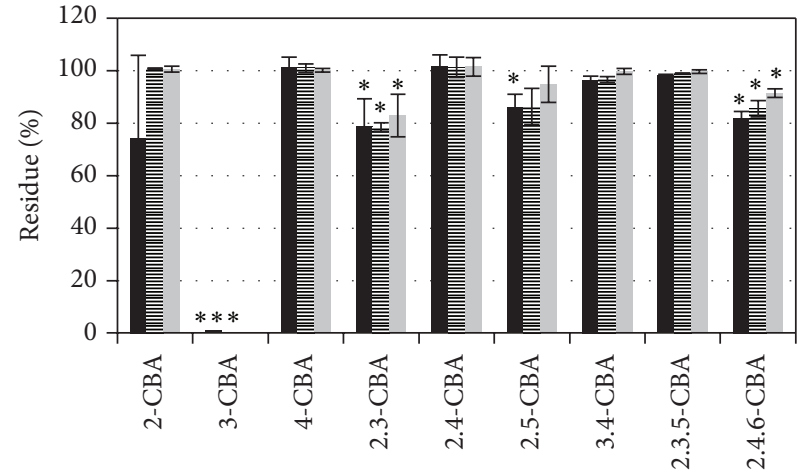

(a)

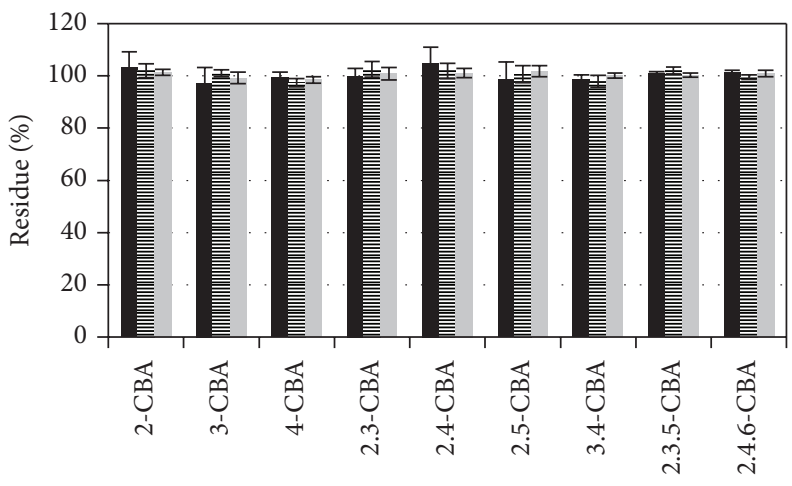

(c)

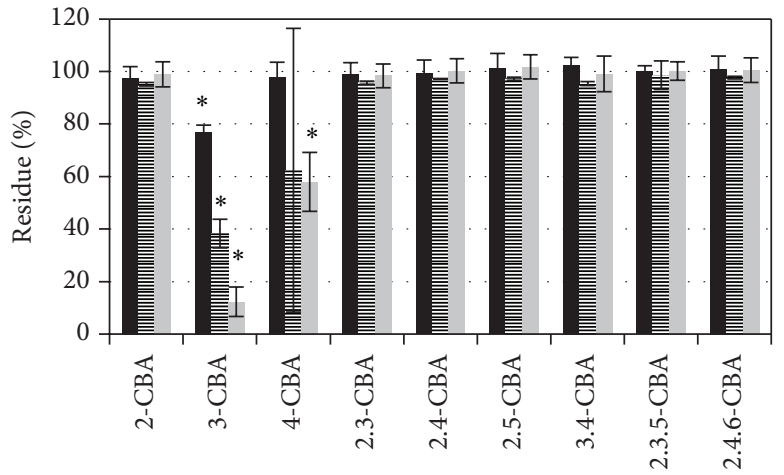

(b)

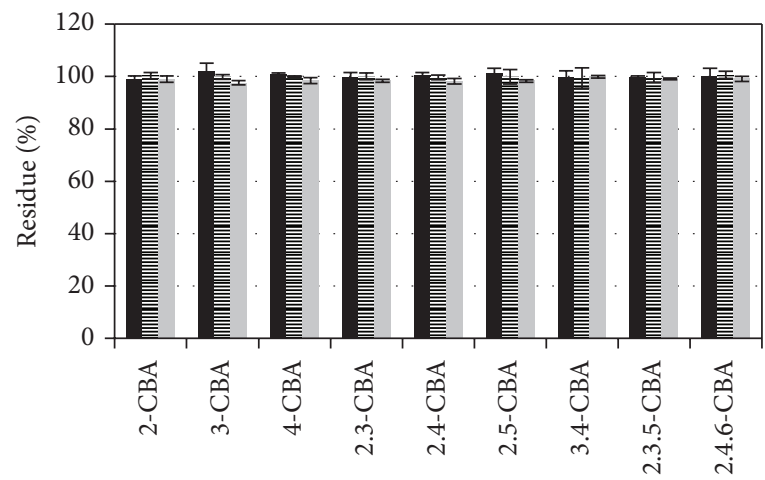

(d)

Figure 4: Degradation of single CBA ((a), (c)) and mixture of CBA ((b), (d)) by strains UH222 (Pandoraea sp.) ((a), (b)) and control ((c), (d)). Black bar in minimal medium, stripped bar in minimal medium with exudates of black nightshade (Solanum nigrum), and grey bar in minimal medium with exudates of tobacco (Nicotiana tabacum). Stars indicate the statistically significant CBA removal (ANOVA).

plant root exudates [24]. Plant exudates from Elymus dauricus have been shown to reduce 2-CBA levels [13]. Hernandez et al. [25] demonstrated that the amendment of soil by plant residues containing terpenes can promote the metabolism of PCBs.

In experiments where we tested root exudates from black nightshade and tobacco, changes were observed in degradation specificity caused by the addition of plant root exudates. For most strains, plant root exudates stopped or slowed degradation of CBAs when CBAs were added either individually or in a mixture (Figures 1-4). However, there were three strains which did not follow this pattern when exposed to 3-CBA and 4-CBA. Strain A18 originally degraded 2-CBA and 3-CBA (Figure 2) when CBAs were tested individually in the presence of exudates from both tested plant species. The same A18 strain, with the mixture of CBAs, acquired 4-CBA degradation activity. Strain UH82 lost the potential to degrade 4-CBA but obtained 3-CBA degradation activity when exudates of tobacco were used for individual or CBA mixture degradation tests (Figure 3). Exudates of black nightshade did not have this effect on strain UH82 in individual CBA degradation tests, but black nightshade exudates preserved 4-CBA degradation activity and induced 3-CBA degradation in the mixture of CBAs. Strain UH133, in the presence of black nightshade exudates, obtained 4-CBA degradation activity on CBAs mixture (Figure 3); however, tobacco exudates did not induce 4 -CBA activity.
These changes in specificity can be generated due to induction or inhibition of enzymes from different CBA pathways by compounds present in plant root exudates. Most of the plant exudates contain 4-hydroxybenzoic acid [26], an intermediate in the 4-CBA degradation pathway. The presence of 4-hydroxybenzoic acid can either inhibit the degradation of 4-CBA (inhibition of reaction by high concentration of product), as in the case of strain UH82 with tobacco root exudates, or induce the degradation of 4CBA as in strain UH133 cultivated with black nightshade root exudates. In the second case the induction can be caused by stimulation of 4-hydroxybenzoic acid degradation pathway which can consequently lead to stimulation of 4CBA degradation pathway. In the case of strain UH133 this effect could be so dominant that it could cause a preference of 4-CBA degradation prior to 3-CBA degradation.

\section{Conclusion}

This study clearly demonstrated that from the strain degradation ability determined on individually added CBA it is difficult to define strain degradation effectiveness on a complex mixture of CBAs. Therefore, practical use of microbial strains for decontamination requires choosing strains with wide degradation abilities determined on mixture of pollutants. From strains that were tested, most promising ones are A18 and UH82, thanks to their degradation of CBAs 
mixture. Also cooperation of different organisms can increase efficiency of decontamination, for example, cooperation of plants and microorganisms. Results indicate that combination with black nightshade will be potentially most suitable for decontamination.

\section{Abbreviations}

CBA: Chlorobenzoic acid

PCB: Polychlorinated biphenyl.

\section{Conflict of Interests}

The authors declare that there is no conflict of interests regarding the publication of this paper.

\section{Acknowledgments}

The work was supported by Grant GAČR 525/09/1058 and EU project MINOTAURUS (FP7-KBBE-2010-4/265946).

\section{References}

[1] V. Matějů, Kompendium Sanačních Technologií, Vodní zdroje Ekomonitor spol s. r. o., Chrudim, Czech Republic, 2006.

[2] S. A. Adebusoye, F. W. Picardal, M. O. Ilori, and O. O. Amund, "Influence of chlorobenzoic acids on the growth and degradation potentials of PCB-degrading microorganisms," World Journal of Microbiology and Biotechnology, vol. 24, no. 7, pp. 1203-1208, 2008.

[3] J. D. Scholten, K.-H. Chang, P. C. Babbitt, H. Charest, M. Sylvestre, and D. Dunaway-Mariano, "Novel enzymic hydrolytic dehalogenation of a chlorinated aromatic," Science, vol. 253, no. 5016, pp. 182-185, 1991.

[4] W. J. Hickey and D. D. Focht, "Degradation of mono-, di-, and trihalogenated benzoid acids by Pseudomonas aeruginosa JB2," Applied and Environmental Microbiology, vol. 56, no. 12, pp. 3842-3850, 1990.

[5] D. K. Chatterjee, S. T. Kellogg, S. Hamada, and A. M. Chakrabarty, "Plasmid specifying total degradation of 3-chlorobenzoate by a modified ortho pathway," Journal of Bacteriology, vol. 146, no. 2, pp. 639-646, 1981.

[6] M. A. Providenti and R. C. Wyndham, "Identification and functional characterization of CbaR, a MarR-like modulator of the $c b a A B C$-encoded chlorobenzoate catabolism pathway," Applied and Environmental Microbiology, vol. 67, no. 8, pp. 3530-3541, 2001.

[7] J. Krooneman, A. O. Slickers, T. M. Pedro Gomes, L. J. Forney, and J. C. Gottschal, "Characterization of 3-chlorobenzoate degrading aerobic bacteria isolated under various environmental conditions," FEMS Microbiology Ecology, vol. 32, no. 1, pp. 53-59, 2000.

[8] D. H. Pieper, "Aerobic degradation of polychlorinated biphenyls," Applied Microbiology and Biotechnology, vol. 67, no. 2, pp. 170-191, 2005.

[9] W. Reineke and H. J. Knackmuss, "Chemical structure and biodegradability of halogenate aromatic compounds. Substituent effects on 1,2-dioxygenation of benzoic acid," Biochimica et Biophysica Acta, vol. 542, no. 3, pp. 412-423, 1978.
[10] K. Demnerova, H. Stiborova, M. B. Leigh et al., "Bacteria degrading PCBs and CBs isolated from long-term PCB contaminated soil," Water, Air, and Soil Pollution, vol. 3, no. 3, pp. 47-55, 2003.

[11] L. Pavlů, J. Vosáhlová, H. Klierová, M. Prouza, K. Demnerová, and V. Brenner, "Characterization of chlorobenzoate degraders isolated from polychlorinated biphenyl-contaminated soil and sediment in the Czech Republic," Journal of Applied Microbiology, vol. 87, no. 3, pp. 381-386, 1999.

[12] B. S. Hernandez, F. K. Higson, R. Kondrat, and D. D. Focht, "Metabolism of and inhibition by chlorobenzoates in Pseudomonas putida P111," Applied and Environmental Microbiology, vol. 57, no. 11, pp. 3361-3366, 1991.

[13] S. D. Siciliano and J. J. Germida, "Degradation of chlorinated benzoic acid mixtures by plant-bacteria associations," Environmental Toxicology and Chemistry, vol. 17, no. 4, pp. 728-733, 1998.

[14] W. J. J.van den Tweel, J. B. Kok, and J. A. M. de Bont, "Reductive dechlorination of 2,4-dichlorobenzoate to 4-chlorobenzoate and hydrolytic dehalogenation of 4-chloro-4-bromo-, and 4iodobenzoate by Alcaligenes denitrificans NTB-1," Applied and Environmental Microbiology, vol. 53, no. 4, pp. 810-815, 1987.

[15] S. A. Adebusoye and M. Miletto, "Characterization of multiple chlorobenzoic acid-degrading organisms from pristine and contaminated systems: mineralization of 2,4-dichlorobenzoic acid," Bioresource Technology, vol.102, no. 3, pp. 3041-3048, 2011.

[16] G. Baggi, S. Bernasconi, M. Zangrossi, L. Cavalca, and V. Andreoni, "Co-metabolism of di- and trichlorobenzoates in a 2-chlorobenzoate-degrading bacterial culture: effect of the position and number of halo-substituents," International Biodeterioration and Biodegradation, vol. 62, no. 1, pp. 57-64, 2008.

[17] M. Muzikáŕ, Z. Křesinová, K. Svobodová et al., "Biodegradation of chlorobenzoic acids by ligninolytic fungi," Journal of Hazardous Materials, vol. 196, pp. 386-394, 2011.

[18] G. Baggi and M. Zangrossi, "Degradation of chlorobenzoates in soil suspensions by indigenous populations and a specialized organism: interactions between growth and non-growth substrates," FEMS Microbiology Ecology, vol. 29, no. 4, pp. 311-318, 1999.

[19] S. D. Siciliano and J. J. Germida, "Enhanced phytoremediation of chlorobenzoates in rhizosphere soil," Soil Biology and Biochemistry, vol. 31, no. 2, pp. 299-305, 1999.

[20] S. D. Siciliano and J. J. Germida, "Bacterial inoculants of forage grasses that enhance degradation of 2-chlorobenzoic acid in soil," Environmental Toxicology and Chemistry, vol. 16, no. 6, pp. 1098-1104, 1997.

[21] M. Macková, B. Vrchotová, K. Francová et al., “Biotransformation of PCBs by plants and bacteria-consequences of plantmicrobe interactions," European Journal of Soil Biology, vol. 43, no. 4, pp. 233-241, 2007.

[22] K. Deavers, T. Macek, U. G. Karlson, and S. Trapp, "Removal of 4-chlorobenzoic acid from spiked hydroponic solution by willow trees (Salix viminalis)," Environmental Science and Pollution Research, vol. 17, no. 7, pp. 1355-1361, 2010.

[23] T. Macek, M. Macková, and J. Káš, "Exploitation of plants for the removal of organics in environmental remediation," Biotechnology Advances, vol. 18, no. 1, pp. 23-34, 2000.

[24] M. Mackova, T. Macek, and D. N. Dowling, Eds., Phytoremediation and Rhizoremediation, Theoretical Background, Focus on Biotechnology, Springer, Dordrecht, The Netherlands, 2006. 
[25] B. S. Hernandez, S.-C. Koh, M. Chial, and D. D. Focht, "Terpene-utilizing isolates and their relevance to enhanced biotransformation of polychlorinated biphenyls in soil," Biodegradation, vol. 8, no. 3, pp. 153-158, 1997.

[26] A. N. Seal, J. E. Pratley, T. Haig, and M. An, "Identification and quantitation of compounds in a series of allelopathic and nonallelopathic rice root exudates," Journal of Chemical Ecology, vol. 30, no. 8, pp. 1647-1662, 2004. 

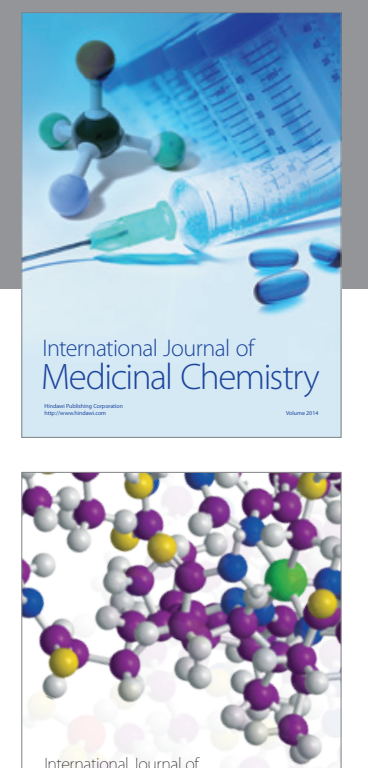

\section{Carbohydrate} Chemistry

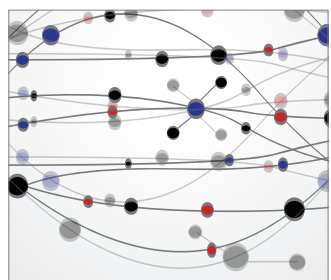

The Scientific World Journal
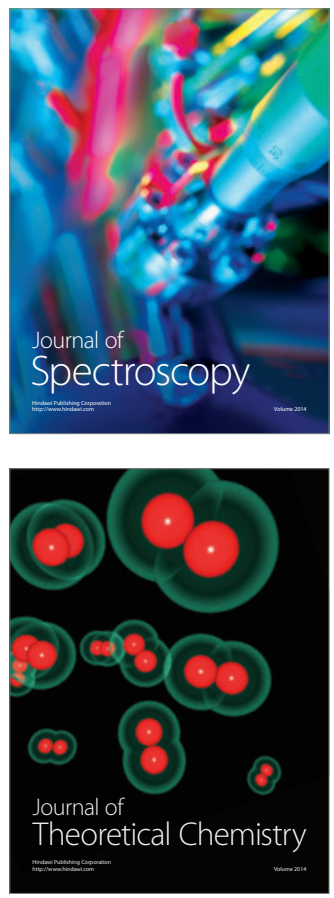
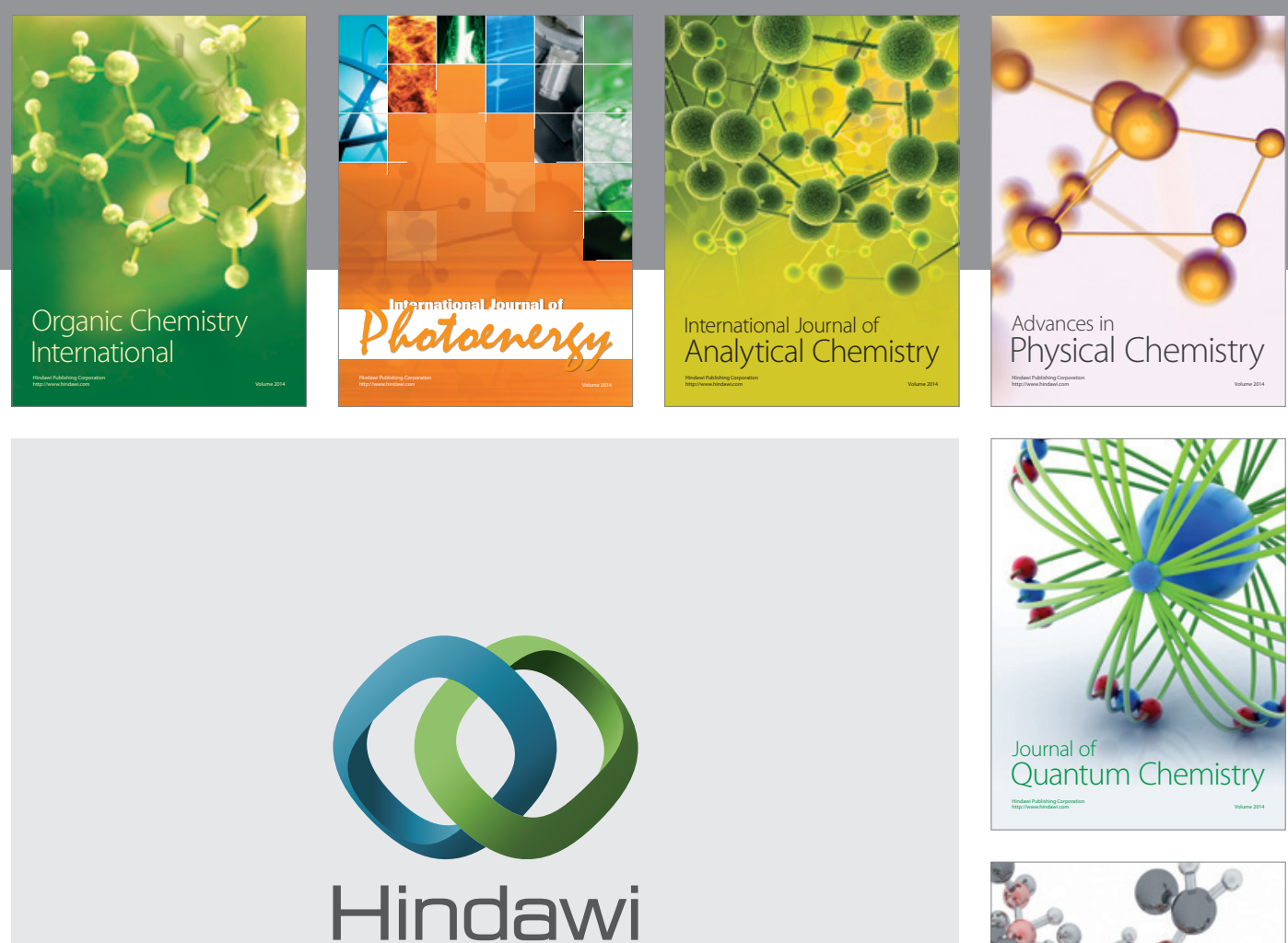

Submit your manuscripts at

http://www.hindawi.com

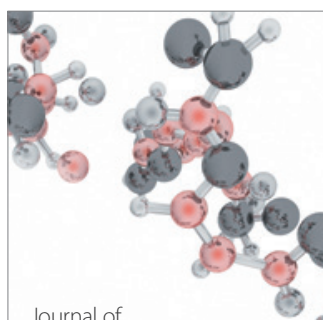

Analytical Methods

in Chemistry

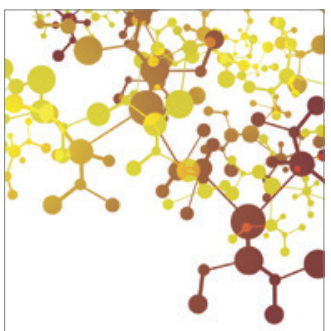

Journal of

Applied Chemistry

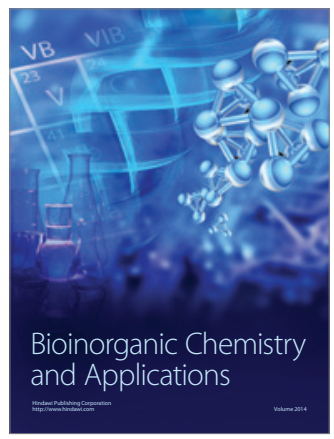

Inorganic Chemistry
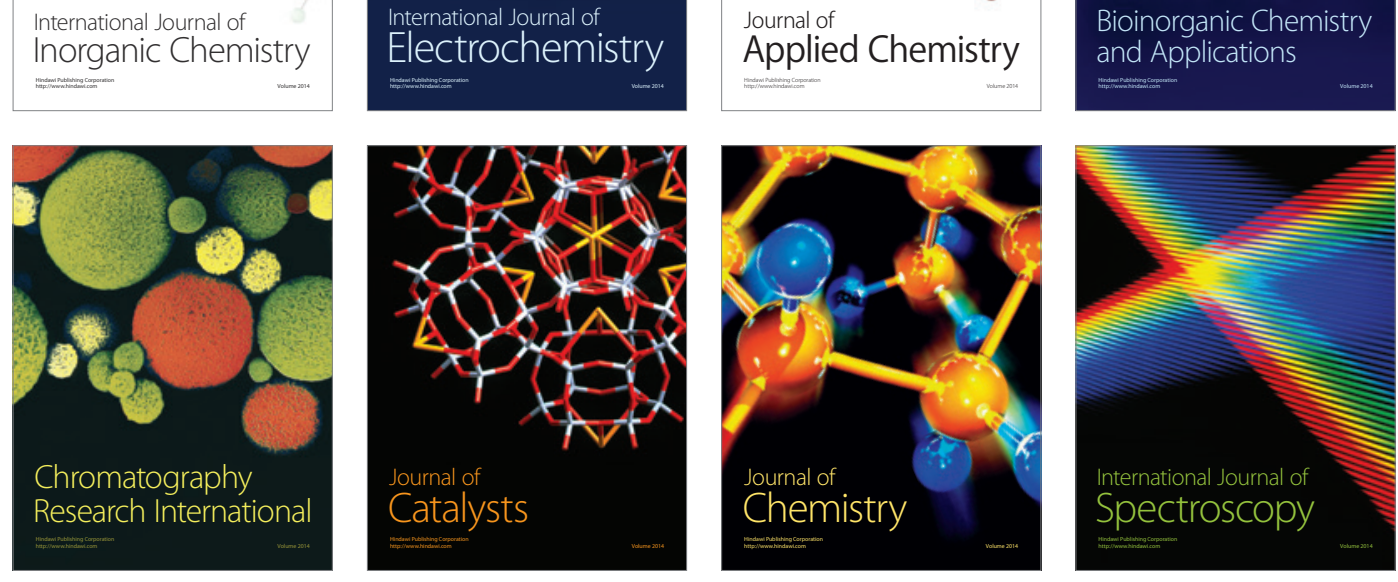